\title{
A insegurança da posse do solo urbano em Minas Gerais
}

\author{
Insecure land tenure in the urban areas of Minas Gerais
}

Paulo Coelho Ávila ${ }^{[a]}$, Frederico Poley Martins Ferreira ${ }^{[b]}$

${ }^{[a]}$ Ministério do Planejamento, Brasília, DF, Brasil
${ }^{[b]}$ Fundação João Pinheiro, Belo Horizonte, MG, Brasil

\section{Resumo}

Neste artigo, são discutidas as características relacionadas à insegurança da posse do solo urbano de Minas Gerais, a partir dos dados da Pesquisa por Amostra de Domicílios (PAD) desse Estado, do ano de 2013, com o desenvolvimento, de forma inédita, de questões específicas sobre o tema. As análises consideraram aspectos da propriedade do terreno dos domicílios próprios urbanos referentes à existência de diferentes instrumentos de garantia da posse e seu registro formal, relacionados aos tipos de edificação, localização em área subnormal, padrão construtivo da edificação, acesso à infraestrutura, ente emissor dos títulos e outros aspectos. Entre os principais resultados, destacam-se: a identificação da totalidade de domicílios próprios com problemas fundiários e a sua disseminação pelo estoque de moradias não apenas nas áreas subnormais, além da demonstração da inexistência de interdependência entre problemas fundiários, precariedade da edificação ou acesso à infraestrutura. Foi identificado também que cerca de 50\% dos domicílios com problemas fundiários estão relacionados, principalmente, a imóveis titulados, mas não registrados, conduzindo à fragilização do direito de moradia.

Palavras-chave: Insegurança da posse. Informalidade. Propriedade fundiária. Titulação. Regularização.

\section{Abstract}

This paper discusses characteristics of the insecure land tenure in the state of Minas Gerais, in Brazil, by using data from the Sample Survey of Minas Gerais Household (PAD-MG) of 2013. This survey presents specific questions on this subject for the first time in Brazil. We analyze aspects of land ownership of the urban owned households regarding the existence of different types of titles and their official register with relation to housing types, location in subnormal areas, construction standards, infrastructure provision, public or private titling and other features. We identified the amount of urban households with insecure land tenure and that it is spread over the entire stock of urban households, not only over the subnormal settlements. We also found that there is no interdependence between unsafe land ownership and house or settlement precariousness. In addition, we found that about $50 \%$ of insecure land tenure is mainly related to titles that lack formal registration.

Keywords: Insecure land tenure. Informality. Land ownership. Titling. Regularization.

PCA é Analista de Infraestrutura do Ministério do Planejamento; Mestre em Planejamento Urbano, e-mail: avilapc@gmail.com FPMF é pesquisador da Fundação João Pinheiro; Doutor em Demografia, e-mail: frederico.poley@fjp.mg.gov.br 


\section{Introdução}

Quando se trata da irregularidade fundiária no Brasil, normalmente vem à mente as imagens das favelas e dos parcelamentos de solo irregulares e/ou clandestinos. Talvez, a mais marcante ainda seja a imagem das favelas, que afetam fortemente a paisagem das áreas metropolitanas do país, ao estabelecer um forte contraste aos olhos de estudiosos e do público em geral. Esse contraste se estabelece a partir da observação lado a lado de uma cidade legal - planejada, organizada e estruturada segundo um arsenal de leis e normas urbanísticas - e outra ilegal - espaço contingente e anárquico em que se sobrepõem, de maneira contundente, a desorganização do ambiente físico, problemas de ordem social e econômica.

Os parcelamentos de solo irregulares, por sua vez, a meio caminho entre o legal e o ilegal, chamam menos a atenção dos sentidos por apresentarem uma configuração espacial aparentemente organizada. Embora ao olhar mais atento não escape à percepção da baixa qualidade do espaço urbano e das edificações, os demais problemas neles presentes não causam a indignação que as favelas provocam em virtude, talvez, da localização periférica e afastada das áreas centrais.

Igualmente, escapam à percepção do público em geral os problemas e as iniquidades existentes em conjuntos habitacionais construídos no âmbito de programas habitacionais promovidos pelo governo. Afinal de contas, de uma ação pública promovida para prover habitação digna àqueles sem capacidade econômica de acessar os mercados formais de habitação, espera-se que estes respondam adequadamente às necessidades e expectativas sociais, econômicas e legais da população-alvo. 0 que chama a atenção, no máximo, como nos parcelamentos periféricos, é a baixa qualidade arquitetônica e dos espaços públicos desses conjuntos financiados com dinheiro do contribuinte.

Aos diferentes problemas espaciais relacionados aos diversos tipos de assentamentos urbanos precários se soma a questão jurídica ligada à propriedade fundiária. Esse é um problema praticamente invisível aos olhos da maioria, o qual aciona uma larga cadeia de efeitos negativos sobre a vida dos cidadãos, suas famílias e a cidade como um todo.

A imprecisão sobre o domínio do solo, que causa a insegurança da posse de uma habitação, provoca, do lado do cidadão e suas famílias, a fragilização do direito constitucional de moradia. Essa insegurança expõe os ocupantes a riscos de despejos forçados ou a invasões de terceiros, desinteresse na melhoria das condições construtivas da habitação e problemas de ordem social e econômica. Estudos têm demonstrado uma larga cadeia de efeitos positivos após a regularização de uma moradia, como a redução do trabalho infantil (Moura et al., 2009). A segurança da posse de uma moradia, localizada em uma área urbana formalmente reconhecida pela administração local, em última análise, é também um instrumento de inclusão e de cidadania.

Embora esses problemas atinjam mais fortemente as famílias de baixa renda, a falta de titulação da terra ocupada afeta também famílias de classe média e até de alta renda. Bairros e cidades inteiras cresceram em terras com problemas na base fundiária, impedindo a titulação dos imóveis ocupados.

A incerteza quanto ao domínio da terra também é um elemento que dificulta e pode impedir investimentos do Poder Público na melhoria dos serviços urbanos. A aplicação de recursos públicos para construção de equipamentos, construção de moradias e provisão de infraestrutura exige a comprovação da dominialidade das terras. Nesse sentido, a regularidade fundiária é fundamental para o desenvolvimento urbano.

No entanto, apesar da importância da questão fundiária para favorecer investimentos das famílias na melhoria das suas moradias e dos agentes públicos no desenvolvimento urbano, a regularização das terras não tem recebido a merecida atenção. Segundo alguns autores, mais de $20 \%$ da população nos grandes centros urbanos no país vivia em áreas informais no fim do século passado (Maricato, 1999).

As transações imobiliárias informais dos imóveis não registrados não geram receitas de impostos para Estados e municípios. O Imposto sobre Transmissão "Inter Vivos" de Bens Imóveis e de Direitos Reais sobre Imóveis (ITBI), de competência municipal e que exclui as transações com imóveis sem registro, foi responsável por uma arrecadação de cerca de 9 bilhões de reais no país em 2013, o que representou cerca de $10 \%$ do total das receitas tributárias dos municípios brasileiros (FNP, 2014). A regularização desses imóveis, certamente, ampliaria a receita das prefeituras, aumentando os recursos para o desenvolvimento de suas políticas urbanas e reduzindo a dependência de verbas da União.

A economia também poderia ser estimulada a partir da regularização dos imóveis. Além de possibilitar o 
acesso ao crédito para construção e reforma, ampliando os gastos das famílias na melhoria das moradias, a regularização fundiária também permitiria que imóveis fossem usados como garantia em financiamentos para ampliação dos negócios em áreas de baixa renda, alavancando o empreendedorismo.

De Soto (2001) afirma que, apesar do espírito empreendedor das famílias pobres, faltam mecanismos apropriados para que o capital morto representado pelos trilhões de dólares acumulados em imóveis seja destravado, transformando o seu potencial econômico em capital ativo para a produção. Para ele, não é o valor em si dos imóveis que importa, mas como eles se inter-relacionam no sistema legal para a geração de capital, isto é, como o sistema de propriedade legal possibilita que se estabeleça uma rede efetiva de ativos, a partir da articulação adequada das leis oficiais com a ordem social.

Nesse sentido, Acemoglu \& Robinson (2012) destacam que a segurança ao direito de propriedade com instituições inclusivas é central para estimular a atividade econômica e o crescimento econômico, uma vez que aqueles que não possuam tal segurança não estarão dispostos a investir e aumentar a produtividade. Instituições econômicas inclusivas requerem a garantia ao direito de propriedade e oportunidades econômicas para toda a sociedade, e não apenas para uma elite.

North $(1990,2005)$ define as instituições como sendo as regras do jogo, que estipulam o que cada ator da sociedade pode ou não fazer. As instituições são criadas para fornecer segurança às interações econômicas, reduzindo incertezas e induzindo os atores a adquirir as informações essenciais para corrigir seus modelos mentais e alcançar resultados eficientes. Assim é que a propriedade legal, estabelecida por um conjunto de regras, leis e regulamentos, que converte o objeto em si, um imóvel, a uma representação conceitual, o registro, e que transforma o ativo em capital (De Soto, 2001).

0 sistema de propriedade legal irá estabelecer não só a proteção da posse do imóvel, mas também a segurança das transações que envolvem os ativos imobiliários. Ele será o centro de uma rede complexa de conexões, fornecendo aos cidadãos comuns as condições para formarem vínculos com o governo, com o setor privado, e, assim, obterem mercadorias e serviços adicionais (De Soto, 2001).

No entanto, caso o sistema de produção da propriedade formal seja incapaz de proteger a posse dos imóveis por causa de regras inadequadas à ordem social, acrescentando custos de transação, os empreendedores e os cidadãos serão motivados a atuar na informalidade. Essa é uma resposta racional dos agentes que, incapazes de incorporar tais custos para se manter na legalidade, optam pela informalidade e criam o seu próprio sistema de regras extraoficiais para regular suas transações fora da economia formal (De Soto, 1987).

Boschi \& Goldschmidt (1970), analisando as populações faveladas do Estado da Guanabara, identificam a favela como uma forma de adaptação de grupos sociais à cidade, onde setores com baixos salários resolvem suas necessidades habitacionais formando subsistemas urbanos cujos limites são definidos por problemas legais quanto à propriedade dos terrenos e pela preponderância de relações informais de caráter pessoal. Tais relações são assentadas em nítida organização capitalista e com grande vitalidade econômica, tendo como base a exploração de recursos internos próprios e consolidando estratos sociais diferenciados que controlam o acesso e a manipulação desses recursos e as decisões políticas (Boschi \& Goldschmidt 1970).

Boschi \& Goldschmidt (1970) ressaltavam uma preocupação mais abrangente em relação ao problema geral da "marginalidade urbana", na perspectiva do planejamento urbano, na perspectiva do comportamento social e político desses setores e na perspectiva de sua integração na sociedade. Esses autores já destacavam em 1970 ser imperativo conhecer o fenômeno em toda a gama de variações, mas sem generalizá-lo, sob o risco de se aproximar apenas superficialmente da realidade, quando não criando uma distorção dela.

Embora o problema da irregularidade fundiária seja um fenômeno conhecido e onipresente no país há bastante tempo, o quadro da informalidade no Brasil ainda é incerto. As estimativas são realizadas sobre dados incapazes de oferecer o conhecimento da real magnitude desse problema, tanto em termos quantitativos quanto em relação à qualificação da insegurança da posse das moradias no Brasil.

0 presente artigo se dedica a caracterizar descritivamente o quadro de insegurança da posse dos domicílios urbanos em Minas Gerais, a partir de dados da Pesquisa por Amostra de Domicílios (PAD), do ano de 2013 (FJP, 2014), realizada pela Fundação João Pinheiro. Esta pesquisa traz pela primeira vez, no país, um conjunto de dados bastante específico 
sobre a segurança da posse dos domicílios em termos da titulação e do registro dos terrenos dos domicílios próprios urbanos. Essas informações oferecem novos conhecimentos acerca do problema fundiário no Estado, podendo abrir novas perspectivas de políticas para resgatar os ativos imobiliários à economia formal, auxiliando no desenvolvimento urbano do Estado.

\section{Informações do IBGE sobre irregularidade fundiária}

Nas pesquisas nacionais, a insegurança da posse das moradias urbanas está associada aos assentamentos irregulares, que são classificados, grosso modo, em favelas ou loteamentos irregulares/clandestinos. Tais assentamentos recebem diferentes denominações regionais igualmente genéricas, nos quais os elementos concretos que caracterizam a insegurança da posse não são claramente identificados.

0 cenário fica mais turvo quando se considera tipologias de assentamentos ou de ocupações irregulares não classificadas como favelas ou loteamentos irregulares. Um exemplo é o caso dos conjuntos habitacionais implantados pelo Poder Público, que, em alguns casos, apresentam problemas na base fundiária, o que impede a titulação das unidades aos beneficiários. Origem indefinida do imóvel, cadeias dominiais sem clareza ou fraudadas, registros de imóveis efetuados com informações insuficientes ou inválidas, parcelamentos de solo urbanos em desconformidade com as normas urbanísticas não são incomuns e podem estar na base da falta de registro de uma moradia.

O Instituto Brasileira de Geografia e Estatística (IBGE) não qualifica, de modo objetivo, a formalidade da propriedade ou da posse dos domicílios nos seus levantamentos. A Pesquisa de Informações Básicas Municipais (IBGE, 2011b), ou Perfil dos Municípios do Brasil, por exemplo, conhecida também como MUNIC, indica os municípios que possuem ocorrência em seu território de assentamentos informais, a partir da autodeclaração das prefeituras. A última edição da pesquisa com tais informações é a de 2011, que revelou que, dos 5.565 municípios brasileiros existentes à época, $57 \%$ deles indicaram a existência de favelas ou de loteamentos irregulares, ou ambos. A Figura 1 mostra a ocorrência de favelas e de loteamentos irregulares por tamanho de municípios.

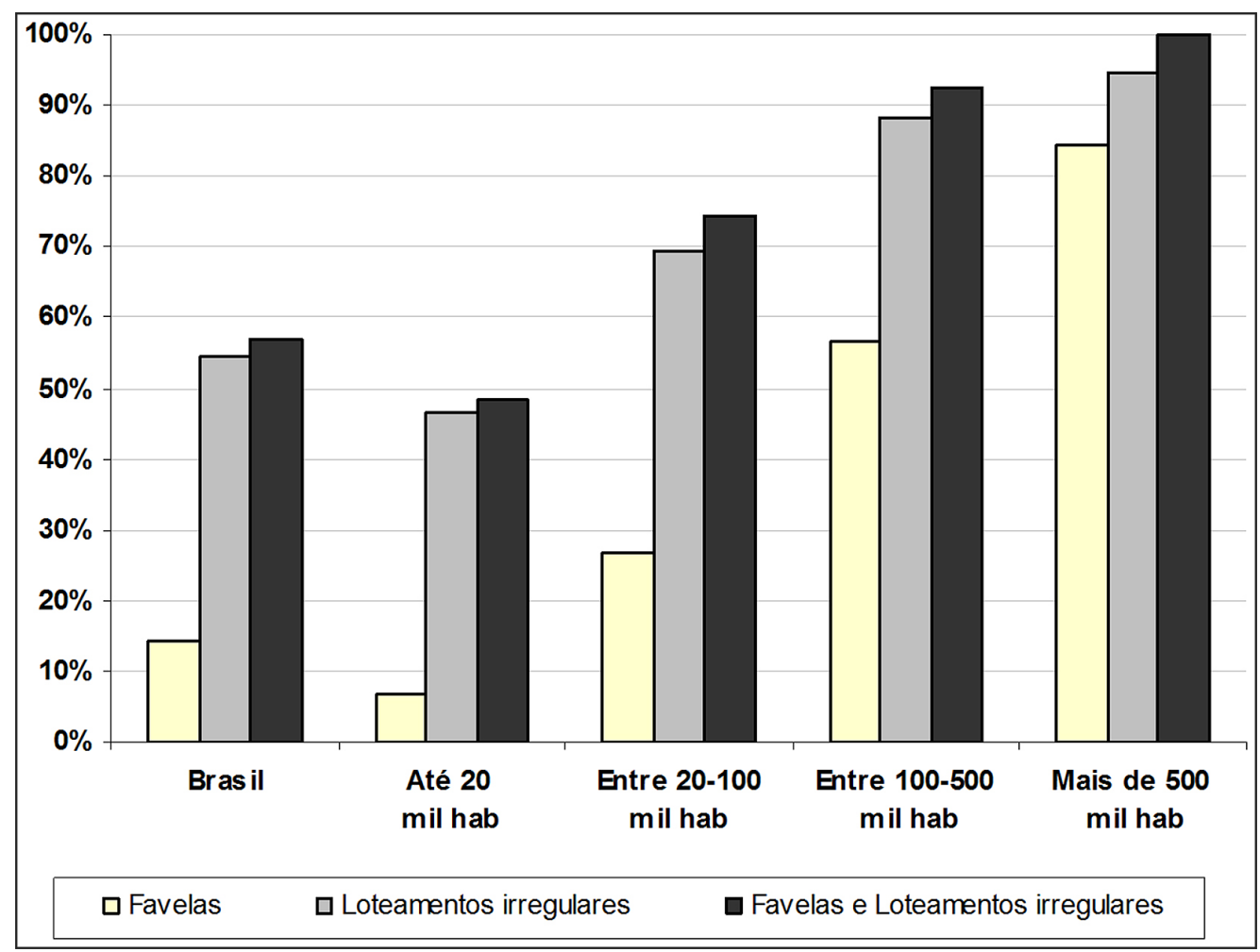

Figura 1 - Irregularidade fundiária do Brasil e por tamanho dos municípios Fonte: IBGE (2011a). 
Predomina, no Brasil, a ocorrência dos loteamentos irregulares em relação às favelas, tanto em termos gerais como por porte dos municípios, especialmente nos de menor tamanho. No entanto, à medida que o porte dos municípios aumenta, mais municípios apresentam assentamentos em que a insegurança da posse das moradias pode estar presente. Considerando os 38 municípios com mais de 500 mil habitantes em 2011, que reuniam 34\% da população urbana no Brasil, todos relataram possuir favela ou loteamento irregular, dos quais $84 \%$ deles possuíam favelas, e 95\%, loteamentos irregulares (ou ambos).

No entanto, nos municípios com população de até 100 mil habitantes, apenas $12 \%$ relataram possuir favelas, enquanto $53 \%$ afirmaram possuir loteamentos irregulares. Esses municípios representam 95\% dos municípios brasileiros e concentram $37 \%$ da população urbana do país. Assim, embora as favelas continuem a ser a face mais visível da informalidade urbana nos grandes centros, o problema de insegurança da posse associado aos loteamentos irregulares pode suplantar os domicílios das favelas, estando disseminado por todo o país, com forte impacto sobre o desenvolvimento dessas regiões.

O IBGE produz informações sobre os chamados setores censitários especiais em aglomerados subnormais nos censos demográficos desde 1991. Essas informações possuem certo grau de generalização, de forma a abarcar a diversidade de assentamentos irregulares do país que recebem denominações como favela, invasão, grota, baixada, comunidade, vila, ressaca, mocambo, palafita, entre outros (IBGE, 2011a).

0 setor censitário especial em aglomerado subnormal é aquele com no mínimo 51 unidades habitacionais e que apresentam: ocupação de terrenos de propriedade alheia (pública ou particular) no momento atual ou em período recente (obtenção do título de propriedade do terreno há dez anos ou menos); posse de pelo menos uma das seguintes características: (i) urbanização fora dos padrões vigentes, refletido por vias de circulação estreitas e de alinhamento irregular, lotes de tamanhos e formas desiguais e construções não regularizadas por órgãos públicos; (ii) precariedade de serviços públicos essenciais.

As informações dos aglomerados subnormais, no entanto, são limitadas ao desconsiderar áreas de assentamentos que não apresentem as características indicadas. Além disso, o seu foco não é a insegurança da posse das moradias, a qual é endereçada apenas indiretamente nos critérios de identificação desses setores censitários.

Os resultados do Censo de 2010 revelaram existir no Brasil 3,2 milhões de domicílios ocupados em aglomerados subnormais, dos quais mais de $95 \%$ se localizavam em áreas urbanas. Esse número dobra o total encontrado em 2000, o que pode ser atribuído, em parte, às mudanças metodológicas ocorridas na pesquisa de 2010 em relação à pesquisa de 2000.

De acordo com os dados de 2010, cerca de 11 milhões de pessoas, ou $6 \%$ da população do Brasil, viviam nos aglomerados subnormais, enquanto apenas $5,6 \%$ dos domicílios ocupados do país se localizavam nesses setores. As maiores contribuições no total do país foram dos Estados de São Paulo (23\%), Rio de Janeiro (19\%), Pará (10\%) e Bahia (9,4\%), totalizando mais de $61 \%$ dos domicílios em aglomerados subnormais do país. No entanto, os Estados mais afetados pelos domicílios em aglomerados subnormais foram Pará, Amazonas, Amapá e Pernambuco, que, além do Rio de Janeiro, apresentam mais de $10 \%$ de seus domicílios nesses setores. Já Minas Gerais apresentou apenas 2,8\% dos seus domicílios em aglomerados subnormais.

Outras informações censitárias com interesse para a temática da irregularidade fundiária dizem respeito às condições de ocupação dos domicílios particulares permanentes, que são classificados como alugados, próprios, cedidos ou com outra condição de ocupação. No caso dos domicílios próprios, os censos de 1991 e 2000 apresentavam ainda informação sobre a condição de ocupação do terreno, isto é, se o terreno era também próprio ou não. Em 2010, não houve a aplicação dessa pergunta.

As respostas a tais perguntas podem refletir a percepção subjetiva do entrevistado acerca da condição do seu imóvel. Mesmo em uma situação de insegurança da posse, os respondentes podem considerar que o terreno em que sua casa está assentada seja próprio, considerando a aquisição de boa-fé e a ocupação do solo sem contestação por longos anos. Nesses casos, se o imóvel tem ou não um registro formal, isso não é captado pela pesquisa.

Os dados dos censos de 1980 a 2010 indicam que a proporção de domicílios urbanos informados como próprios aumentou de $60,3 \%$ para $74,7 \%$, porém entre 2000 e 2010 essa proporção caiu para 72,7\%. A condição de ocupação do terreno só pode ser avaliada entre 1991 e 2000. Em 1991, o número dos domicílios particulares próprios, mas não o terreno, 
alcançou 1,95 milhão de unidades, enquanto que, em 2000, o total de domicílios próprios sem terreno próprio chegou a cerca de 2,16 milhões.

Embora esses números indiquem um aumento absoluto no total desses domicílios, em termos proporcionais os números indicam uma queda, isto é, entre 1991 e 2000 a participação dos domicílios cuja propriedade do terreno era incerta caiu de 10,2\% para 7,8\% em relação aos domicílios próprios. Não é possível afirmar se essa queda relativa indicava uma tendência, uma vez que no Censo de 2010 a pergunta sobre a posse do terreno foi descontinuada.

\section{PAD-MG 2013 e a situação fundiária das moradias em Minas Gerais}

A PAD de Minas Gerais (FJP, 2014) é um levantamento bienal de dados com amostra de 18 mil domicílios em todo o Estado mineiro e se encontra em sua terceira edição. A distribuição da amostra dos domicílios leva em consideração a necessidade de desagregação territorial, e as variáveis captadas pela pesquisa são significativas tanto para as 12 mesorregiões oficialmente classificadas pelo IBGE quanto para as diferentes regiões de planejamento usadas pelo governo do Estado.

A pesquisa incluiu diversos tipos de questões associadas à população, economia, desenvolvimento social, entre outros aspectos relacionados às diversas políticas públicas e sua avalição, e incluiu também, de forma inédita, uma série de quesitos elaborados para a questão fundiária. Isso permitiu diversos cruzamentos que, além da obtenção de uma melhor estimativa do número real de moradias que possuem questões relativas à posse da terra, permitiram qualificar as condições de insegurança da posse da terra.

Nesse sentido, os domicílios identificados com insegurança da posse do solo, isto é, domicílios próprios com condições inadequadas de titulação, por tipo de título, e de registro dos terrenos, foram confrontados com outras informações da pesquisa, tais como a localização em áreas subnormais, tipos de edificação, condições das paredes externas das edificações, tipo de escoadouro dos esgotos, ocupação de áreas públicas e ente emissor dos títulos (se público ou privado). Essas questões combinadas permitiram estabelecer uma visão mais clara tanto em termos relativos como absolutos da dimensão da insegurança da posse da terra no Estado de Minas Gerais.

\section{Os domicílios urbanos em áreas subnormais}

Em Minas Gerais, foram encontrados um total de 5.470 .410 domicílios em áreas urbanas, ou 86,5\% dos domicílios totais (FJP, 2014). Na aplicação do questionário, o entrevistador registrou, inicialmente, se o domicílio estava localizado em área subnormal (aglomerado, favela) ou em outra área, o que permitiu uma primeira identificação sobre a condição de irregularidade das moradias. Tal classificação se baseia em critérios definidos no treinamento dos recenseadores, orientados a definir tais domicílios segundo a forma de ocupação do espaço urbano, identificação por parte dos entrevistados e padrão de acabamento da edificação. Por esse motivo, as informações da PAD de Minas Gerais sobre as áreas subnormais devem ser observadas com cuidado, inclusive quando comparadas aos dados de outros levantamentos que utilizam outras metodologias.

Os entrevistadores registraram 866.696 domicílios localizados em áreas subnormais, ou 15,8\% do total dos domicílios urbanos. Dos domicílios em áreas subnormais, 64,4\% foram relatados como próprios (já pagos ou ainda pagando), 24,5\%, como alugados, 10,2\%, como cedidos, e $0,9 \%$, com outra condição de ocupação, proporções próximas às encontradas no conjunto dos domicílios fora das áreas subnormais (Tabela 1).

Como a maior parte dos domicílios situados emáreas subnormais foi informada como própria, a pesquisa então perguntou se os terrenos também eram próprios e, em caso positivo, se eram titulados e registrados. Os dados da PAD de Minas Gerais mostraram que, mesmo nas áreas identificadas como subnormais, era grande a incidência de terrenos titulados, embora nem todos sejam formalmente registrados.

Nas áreas subnormais, menos de $10 \%$ dos domicílios próprios não possuíam terrenos próprios, enquanto que, nas demais áreas, esse total foi de 4,9\%. Em termos absolutos, o número de terrenos indicados como não próprios fora das áreas subnormais era cerca de três vezes maior que nas áreas subnormais, isto é, $146 \mathrm{mil}$ contra 50,2 mil domicílios (FJP, 2014).

A Tabela 2 apresenta os números referentes aos terrenos próprios, próprios com documentos emitidos e os registrados. Neste trabalho, os dados apresentados das respostas dos entrevistados consideram apenas as respostas válidas. É possível verificar que 83,6\% dos terrenos informados como próprios nas áreas 
Tabela 1 - Características dos domicílios em relação à sua condição de ocupação (alugados, próprios ou cedidos)

\begin{tabular}{|c|c|c|c|c|c|}
\hline & \multicolumn{2}{|c|}{ Área subnormal } & \multicolumn{2}{|c|}{ Outro } & \multirow{2}{*}{ Total } \\
\hline & Total & $\%$ & Total & $\%$ & \\
\hline Próprios & 558.013 & $64,4 \%$ & 3.120 .906 & $67,8 \%$ & 3.678 .919 \\
\hline Alugados & 212.082 & $24,5 \%$ & 1.050 .565 & $22,8 \%$ & 1.262 .647 \\
\hline Cedidos & 89.196 & $10,3 \%$ & 409.456 & $8,9 \%$ & 498.652 \\
\hline Outra condição & 7.405 & $0,9 \%$ & 22.787 & $0,5 \%$ & 30.192 \\
\hline Total & 866.696 & $100 \%$ & 4.603.714 & $100 \%$ & 5.470 .410 \\
\hline
\end{tabular}

Fonte: FJP (2014).

Tabela 2 - Condição de ocupação em relação aos domićlios próprios

\begin{tabular}{|c|c|c|c|c|c|c|}
\hline & \multicolumn{2}{|c|}{ Área subnormal } & \multicolumn{2}{|c|}{ Outro } & \multicolumn{2}{|c|}{ Domićilios próprios } \\
\hline & Total & \%* & Total & $\% *$ & Total & $\%^{*}$ \\
\hline Domicilios próprios & 533.360 & $100 \%$ & 2.995 .756 & $100 \%$ & 3.529 .116 & $100 \%$ \\
\hline Domićlios próprios com terrenos próprios & 479.895 & $90,0 \%$ & 2.819 .608 & $94,1 \%$ & 3.299 .503 & $93,5 \%$ \\
\hline Terrenos próprios com títulos emitidos & 401.406 & $75,2 \%$ & 2.577 .440 & $86,0 \%$ & 2.978 .846 & $84,4 \%$ \\
\hline Títulos emitidos e registrados & 329.608 & $61,8 \%$ & 2.278 .885 & $76,0 \%$ & 2.608 .493 & $73,9 \%$ \\
\hline
\end{tabular}

*Porcentagens se referem aos domićlios próprios.

Fonte: FJP (2014).

subnormais foram titulados, contra $91,4 \%$ nas demais áreas. Finalmente, dos terrenos titulados nas áreas subnormais, $81 \%$ estavam registrados, ao passo que, nas demais áreas, esse total foi de $88 \%$.

Em resumo, nas áreas classificadas como subnormais, $62 \%$ dos domicílios próprios - excluindo os alugados, cedidos e com outra condição de ocupação - apresentaram situação fundiária regular, enquanto nas demais áreas essa proporção foi de $76 \%$. Percebe-se que o problema da insegurança da posse, embora proporcionalmente mais elevado nas áreas subnormais, não é exclusivo delas. 0 número absoluto de domicílios próprios fora das áreas subnormais que não possuem documento de posse da terra ou que o possuem, mas não estão registrados, é cerca de duas vezes o número de domicílios nas mesmas condições nas áreas subnormais.

Esses dados indicam que a classificação das áreas subnormais não é suficiente para a captação dos problemas ligados à insegurança da posse das moradias. Além disso, mesmo que o número total de domicílios próprios urbanos com terrenos titulados corresponda a 74\% do total, essa não é uma situação a ser comemorada.
Quantificando os domicílios urbanos quanto à insegurança da posse

As áreas subnormais captam apenas uma parte do problema, que se alastra pelo estoque de moradias urbanas. No presente estudo, foram tratados apenas os domicílios identificados como próprios já pagos ou ainda pagando, o que pode ser uma limitação para se identificar a magnitude do problema, pois foram excluídos os domicílios alugados, cedidos ou com outra forma de ocupação. Esses domicílios correspondiam a um terço do estoque de domicílios urbanos.

A PAD de Minas Gerais buscou saber se os terrenos dos domicílios próprios também eram próprios, replicando a pergunta aplicada pelo IBGE nos censos de 1991 e 2000. Considera-se que uma moradia assentada em terrenos de terceiros pode expor as famílias a despejos forçados ou a ter a sua moradia tomada. A PAD identificou 196.219 domicílios nessa situação, ou 5,6\% dos domicílios urbanos próprios de Minas Gerais (FJP, 2014).

Das respostas válidas quanto aos domicílios em terrenos não próprios, 91\% eram casas, seguido 
pelos apartamentos com 7,6\%. 0 tipo de edificação identificado pelos entrevistadores é importante no sentido de associar a insegurança da posse à qualidade construtiva do imóvel. Assim, aqueles domicílios identificados como barracos representavam apenas $1,4 \%$ desse total.

A partir dessas respostas, a PAD de Minas Gerais buscou descobrir qual era a situação de titulação e de registro dos terrenos identificados como próprios. 0 entrevistado deveria então responder qual o tipo de documento que possuía, se um título pleno de propriedade, de concessão de uso, uma promessa de compra e venda, um título de legitimação de posse, e se esses documentos eram registrados. 0 detalhamento de cada um desses títulos será feito na próxima seção.

Dos domicílios com terrenos próprios, 156.313 domicílios não possuíam qualquer tipo dos documentos citados, ou 4,4\% dos domicílios próprios urbanos. Novamente, os domicílios sem documentos de posse eram, em sua maior parte, casas, com $92 \%$, enquanto os apartamentos alcançaram 2,1\%. Nesse caso, os barracos sem documentação do terreno aumentaram sua participação para $6 \%$.

Observa-se ainda que, do total de domicílios próprios sem documentação de propriedade do terreno, 63,2\% estavam localizados em áreas particulares. No caso das casas sem documentação do terreno, 30\% delas se localizavam em áreas públicas, assim como $74,5 \%$ dos barracos sem documentação do terreno. No entanto, a totalidade dos apartamentos estava em áreas privadas. Tais números indicam a necessidade de uma ação mais efetiva do Poder Público na regularização das ocupações irregulares de suas áreas, enquanto que, em relação aos apartamentos, as causas da falta da titulação das unidades habitacionais podem estar relacionadas ao licenciamento urbanístico ou às transações imobiliárias.
Finalmente, a pesquisa quis saber se os documentos emitidos em posse dos entrevistados foram registrados nos cartórios de imóveis. Dos documentos emitidos, 312.483 não eram registrados, ou seja, 10,5\% dos títulos emitidos. Em relação aos domicílios próprios urbanos, esse número representou 8,9\%. Os números dos domicílios identificados com insegurança da posse são mostrados na Tabela 3.

Observa-se que o total de domicílios com documentos de titulação não registrados representa quase a soma dos domicílios em terrenos não próprios e em terrenos próprios não titulados. A maior parte dos domicílios com terrenos titulados sem registro é representado por casas, com $94 \%$. No caso dos apartamentos, o número de domicílios cujos documentos não foram registrados é bem próximo ao número de apartamentos situados em terrenos não próprios e em terrenos próprios não titulados. Essa relação se inverte no caso dos barracos, sendo os domicílios sem documentação o mais numeroso, correspondendo ao dobro da soma dos barracos em terrenos não próprios e em terrenos próprios não registrados.

Considerando a soma dos domicílios próprios urbanos sem terreno próprio, sem documentação de titulação da terra e sem registro dos títulos existentes, chega-se a uma participação de 18,8\% de domicílios com insegurança da posse em relação ao total de domicílios próprios urbanos. Caso sejam considerados os domicílios com outra condição de ocupação, uma vez que não possuem uma relação formal de ocupação, seja de compra, aluguel ou cessão, chegaremos a uma proporção total que beira 13\% dos domicílios urbanos totais com insegurança da posse.

A Figura 2 mostra que, dos domicílios próprios identificados com insegurança da posse, aqueles com títulos do terreno não registrados obtiveram a maior

Tabela 3 - Domicilios urbanos próprios em relação à condição de insegurança da posse

\begin{tabular}{|c|c|c|c|c|c|c|c|c|}
\hline & \multicolumn{2}{|c|}{$\begin{array}{l}\text { Domićlios próprios e } \\
\text { terrenos não próprios }\end{array}$} & \multicolumn{2}{|c|}{$\begin{array}{l}\text { Terrenos próprios sem } \\
\text { documento de propriedade }\end{array}$} & \multicolumn{2}{|c|}{$\begin{array}{l}\text { Terrenos próprios com } \\
\text { documento não registrado }\end{array}$} & \multicolumn{2}{|c|}{$\begin{array}{l}\text { Domicílios próprios com } \\
\text { insegurança da posse }\end{array}$} \\
\hline & Total & $\%$ & Total & $\%$ & Total & $\%$ & Total & $\%$ \\
\hline Casa & 178.350 & $90,9 \%$ & 143.388 & $91,7 \%$ & 293.420 & $93,9 \%$ & 615.158 & $92,5 \%$ \\
\hline Apartamento & 14.836 & $7,6 \%$ & 3.274 & $2,1 \%$ & 16.931 & $5,4 \%$ & 35.041 & $5,3 \%$ \\
\hline Barraco & 2.785 & $1,4 \%$ & 9.352 & $6,0 \%$ & 1.750 & $0,6 \%$ & 13.887 & $2,1 \%$ \\
\hline Outros & 248 & $0,1 \%$ & 299 & $0,2 \%$ & 382 & $0,1 \%$ & 929 & $0,1 \%$ \\
\hline Total & 196.219 & $100 \%$ & 156.313 & $100 \%$ & 312.483 & $100 \%$ & 665.015 & $100,0 \%$ \\
\hline
\end{tabular}

Fonte: FJP (2014). 
participação no total com $47 \%$, enquanto $29,5 \%$ eram domicílios sem terreno próprio e $23,5 \%$ eram terrenos sem documentação.

Tal fato pode estar ligado ao desconhecimento dos ocupantes acerca da importância de se registrar no cartório de imóveis um título recebido, de modo a formalizar a posse do imóvel. 0 documento ou título recebido de um particular ou de um ente público só garante a posse do imóvel quando for registrado. Mesmo o registro de uma escritura em um cartório de notas não é suficiente para fornecer tal garantia.

A alta proporção de documentos não registrados pode também ser decorrente de dificuldades para efetuar o registro nos próprios cartórios, tais como: preços elevados de custas e emolumentos para se concretizar o ato registral, que camadas específicas da população não podem arcar; exigências para efetuar o registro não previstas na legislação impostas pelos cartórios por excesso de zelo; pendências relativas à base fundiária do assentamento; eventuais disputas jurídicas que impedem o registro.

Embora a precariedade construtiva das moradias ou dos assentamentos seja associada à questão fundiária, os dados da PAD de Minas Gerais mostram que não necessariamente essas características sejam elementos de um mesmo fenômeno. Nota-se que não há predominância da precariedade das moradias, caracterizada pelo material das paredes externas das moradias, ou das condições da provisão de infraestrutura nos assentamentos, caracterizada pelo tipo de escoamento dos esgotos, com a insegurança da posse. A maioria dos domicílios na condição de insegurança da posse possui materiais adequados das paredes externas (alvenaria ou madeira aparelhada) ou escoadouro dos esgotos ligados à rede pública ou a fossas sépticas (Tabelas 4 e 5).

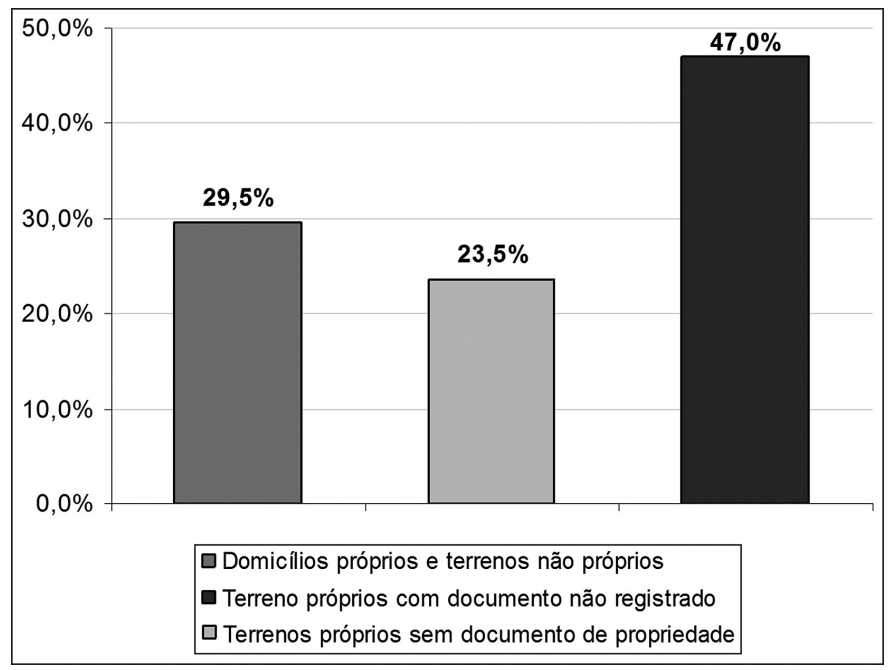

Figura 2 - Domicílios próprios com insegurança da posse

Fonte: FJP (2014).

Tabela 4 - Características dos domicílios em relação ao material predominante das paredes externas

\begin{tabular}{|c|c|c|c|c|c|}
\hline Tipos de domićilios urbanos e condição do terreno & Totais & Adequados & $\%$ & $\begin{array}{c}\text { Não } \\
\text { Adequados }\end{array}$ & $\%$ \\
\hline Domicílios urbanos totais & 5.470 .410 & 5.368 .980 & $98,1 \%$ & 101.430 & $1,9 \%$ \\
\hline Domicilios urbanos próprios & 3.678 .919 & 3.612 .767 & $98,2 \%$ & 66.152 & $1,8 \%$ \\
\hline Domicílios urbanos próprios e terrenos não próprios & 196.219 & 191.330 & $97,5 \%$ & 4.889 & $2,5 \%$ \\
\hline Domićlios urbanos próprios e terrenos próprios não titulados & 156.313 & 152.653 & $97,7 \%$ & 3.660 & $2,3 \%$ \\
\hline Domicílios urbanos próprios e terrenos próprios titulados sem registro & 312.483 & 307.881 & $98,5 \%$ & 4.602 & $1,5 \%$ \\
\hline Domićlios urbanos próprios com insegurança da posse & 665.015 & 651.864 & $98,0 \%$ & 13.151 & $2,0 \%$ \\
\hline
\end{tabular}

Fonte: FJP (2014). 
Tabela 5 - Características dos domićilios em relação ao tipo de escoadouro do esgoto do banheiro/sanitário

\begin{tabular}{|c|c|c|c|c|c|}
\hline Tipos de domicílios urbanos e condição do terreno & Totais & Adequados & $\%$ & $\begin{array}{c}\text { Não } \\
\text { Adequados }\end{array}$ & $\%$ \\
\hline Domićlios urbanos totais & 5.470 .410 & 5.033 .119 & $92,0 \%$ & 305.131 & $5,6 \%$ \\
\hline Domiclilios urbanos próprios & 3.678 .919 & 3.357 .850 & $91,3 \%$ & 226.516 & $6,2 \%$ \\
\hline Domicilios urbanos próprios e terrenos não próprios & 196.219 & 179.038 & $91,2 \%$ & 12.115 & $6,2 \%$ \\
\hline Domićlios urbanos próprios e terrenos próprios não titulados & 156.313 & 124.805 & $79,8 \%$ & 23.372 & $15,0 \%$ \\
\hline Domiclílios urbanos próprios e terrenos próprios titulados sem registro & 312.483 & 276.410 & $86,9 \%$ & 31.637 & $10,0 \%$ \\
\hline Domicílios urbanos próprios com insegurança da posse & 665.015 & 580.253 & $86,5 \%$ & 67.124 & $10,0 \%$ \\
\hline
\end{tabular}

Fonte: FJP (2014).

A participação dos domicílios cuja edificação apresentava condições construtivas inadequadas (paredes externas constituídas por alvenaria sem revestimento, taipa não revestida, material aproveitado ou outro material) nos domicílios com insegurança da posse, nos domicílios urbanos totais ou nos domicílios próprios era praticamente semelhante, em torno de $2 \%$. No entanto, os domicílios com insegurança da posse associados às condições construtivas inadequadas correspondiam a $20 \%$ dos domicílios próprios urbanos e a $13 \%$ dos domicílios urbanos totais, ambos com material inadequado das paredes externas - são valores elevados.

Em termos proporcionais, os domicílios cujos terrenos não são próprios ou não titulados apresentaram mais de $2 \%$ em condições construtivas precárias, ao passo que os domicílios titulados, mas sem registro, representaram apenas 1,5\% em condições construtivas inadequadas. Essa diferença pode estar associada ao fato de que a melhoria das moradias, em geral, é realizada de modo incremental ao longo do tempo, conforme permitem os orçamentos das famílias, especialmente aquelas com restrições monetárias. A falta de titulação da moradia pode ser um fator que desestimula a realização de tais melhorias.

Em relação às condições sanitárias dos assentamentos, 5,6\% dos domicílios urbanos em Minas Gerais não possuíam forma adequada de esgotamento sanitário - esgotos dos banheiros ou sanitários dos domicílios escoados por meio de fossas rudimentares ou lançados em valas, diretamente em rios, lagos ou outras formas. No grupo de domicílios identificados com insegurança da posse, essa proporção foi maior, alcançando $10 \%$ dos domicílios com condições inadequadas de esgotamento sanitário.
Chamou a atenção que os domicílios urbanos com insegurança da posse e esgotamento sanitário inadequado representassem $29,6 \%$ dos domicílios urbanos próprios com esse problema, enquanto eram $22 \%$ dos domicílios urbanos totais com escoamento inadequado - participação mais elevada se comparada àquela representada pela adequação construtiva das moradias.

Merece destaque a participação dos domicílios com terrenos próprios não titulados e titulados sem registro sobre os domicílios totais com insegurança da posse e escoadouro de esgotos inadequados. Enquanto, no primeiro caso, os domicílios com terrenos próprios não titulados participaram com $35 \%$ no total dos domicílios com insegurança da posse e problemas de adequação do esgotamento sanitário, no segundo corresponderam a $47 \%$. Esse fato pode estar relacionado ao vínculo existente entre a provisão de infraestrutura nos loteamentos e o registro.

A Lei Federal 6.766, de 1979, (Brasil, 1979) que trata do parcelamento do solo para fins urbanos, vincula o registro do parcelamento à apresentação da aprovação do loteamento e do comprovante do termo de verificação pela administração local da execução das obras exigidas por legislação municipal. Essas obras devem incluir, no mínimo, as vias de circulação do loteamento, demarcação dos lotes, quadras e logradouros, além de obras de escoamento das águas pluviais. No entanto, muitos municípios ampliam as exigências mínimas da legislação federal, incluindo os vários sistemas de infraestrutura e serviços urbanos.

$\mathrm{Na}$ falta de execução das obras previstas, o inciso $\mathrm{V}$ do artigo 18 da Lei 6.766 (Brasil, 1979) o registro poderá ser feito mediante a aprovação de um cronograma para a execução das obras, acompanhado de competente 
instrumento de garantia. 0 não cumprimento por parte do loteador das obras exigidas pela legislação impede o registro do parcelamento e a titulação dos terrenos.

Como observado, é elevado o número de domicílios próprios com problemas relacionados ao escoamento dos esgotos cujos terrenos são titulados, porém não registrados. Parece reforçar essa hipótese, os domicílios próprios com terrenos próprios que possuem promessa de compra e venda - documento fornecido nas transações de alienação de imóveis (ver próxima seção) - representavam 11\% desses domicílios com forma inadequada de escoadouro dos esgotos, enquanto $32,3 \%$ eram domicílios titulados com tais problemas.

\section{Qualificando os domicílios urbanos quanto ao registro da propriedade}

A propriedade de um imóvel é um direito real, isto é, confere ao seu beneficiário o poder direto sobre alguma coisa a qual pode ser objeto de propriedade. Segundo a Lei 10.406, de 2002, que institui o Código Civil (Brasil, 2002), o proprietário terá a faculdade de usar, gozar e dispor da coisa, além do direito de sequela, ou seja, de reaver a coisa de quem injustamente a detenha ou tenha possuído. A posse, por sua vez, caracteriza-se pelo fato de que aquele que a detém exerce algum dos poderes inerentes à propriedade sem, no entanto, deter a qualidade de proprietário. Enquanto a propriedade é um direito, a posse é um fato.

0 ordenamento jurídico brasileiro protege tanto o proprietário quanto as relações possessórias. 0 direito de moradia, incluído nos direitos sociais na Constituição Federal por meio da Emenda Constitucional no 26, de 2000, é garantido quando um direito real, sob a forma de propriedade, ou a posse de um imóvel, está protegido. Conforme o artigo 1.227 do Código Civil (Brasil, 2002), os direitos reais sobre imóveis constituídos só se adquirem com o registro dos títulos no Cartório de Registro de Imóveis, salvo em casos expressos na legislação.

A transferência de um direito real de propriedade pode depender do cumprimento de condições, originadas por transações onerosas ou gratuitas, estabelecidas por um contrato ou por ato previsto em lei. A condição resolutiva ou suspensiva, ou seja, o motivo para extinção da transferência do direito de propriedade, deve estar claramente estabelecida no teor do seu termo constitutivo, o qual deve ser objeto de registro.

A PAD de Minas Gerais, como afirmado, identifica, dentre quatro tipos de instrumentos de garantia da posse, se foram emitidos e registrados, a saber: título pleno de propriedade, concessão de uso, promessa de compra e venda e legitimação de posse. Esses documentos, quando levados a registro, protegem por via direta o direito de moradia. A Tabela 6 mostra a participação de cada um desses documentos e se foram ou não registrados.

0 título pleno de propriedade é o que dá plenos poderes ao seu possuidor, isto é, o proprietário terá a faculdade de usar, gozar e dispor da coisa, além do direito de sequela. 0 exercício desse direito não é ilimitado e se vincula à função social da propriedade, como estabelece a Constituição Federal de 1988. No levantamento da PAD de Minas Gerais, o título pleno de propriedade era aquele com a maior participação nos títulos emitidos, com $68 \%$ do total.

Nas transações comerciais de alienação de imóveis, a promessa de compra e venda confere ao

Tabela 6 - Domicilios próprios com terrenos próprios e fítulos emitidos e não registrados por tipo de fítulo

\begin{tabular}{|c|c|c|c|c|c|}
\hline \multirow{2}{*}{ Tipo do documento emitido } & \multicolumn{2}{|c|}{ Emitidos } & \multicolumn{2}{|c|}{ Não registrados } & \multirow{2}{*}{$\begin{array}{c}\text { Não registrados } \\
\text { por tipo }\end{array}$} \\
\hline & Total & $\%$ & Total & $\%$ & \\
\hline Título pleno de propriedade & 2.025 .705 & $68,0 \%$ & 102.358 & $32,8 \%$ & $5,1 \%$ \\
\hline Promessa de compra e venda & 534.460 & $17,9 \%$ & 105.838 & $33,9 \%$ & $19,8 \%$ \\
\hline Concessão de uso & 205.867 & $6,9 \%$ & 49.705 & $15,9 \%$ & $24,1 \%$ \\
\hline Legitimaç̦ão de posse & 212.814 & $7,1 \%$ & 54.582 & $17,5 \%$ & $25,6 \%$ \\
\hline Total & 2.978 .846 & $100,0 \%$ & 312.483 & $100,0 \%$ & $10,5 \%$ \\
\hline
\end{tabular}

Fonte: FJP (2014). 
promitente comprador direito real à aquisição do imóvel quando registrada no Cartório de Registro de Imóveis. Tal instrumento é a expectativa de realização de um direito real, e o promitente comprador, titular desse direito, pode exigir do promitente vendedor (ou de terceiros), de quem os direitos serão cedidos, a outorga da escritura definitiva de compra e venda, conforme disposto no instrumento preliminar. Se houver recusa, poderá requerer ao juiz a adjudicação do imóvel (ver Código Civil, art. 1418 - Brasil, 2002).

A promessa de compra e venda foi o documento com a segunda maior incidência dentre os títulos emitidos aos terrenos próprios, representando com 17,9\% do total. A outorga da escritura definitiva de compra e venda se converte em título pleno de propriedade quando do seu registro no Cartório de Imóveis.

A transferência de direitos reais de um proprietário a terceiros pode ser gratuita ou onerosa, individual ou coletiva, e realizada mediante contratos de concessão de uso, nos quais o proprietário apenas transfere a alguém a faculdade de usar a propriedade durante a vigência do contrato. 0 uso é um usufruto restrito, possuindo as mesmas características de direito real, mas distinguindo-se pelo fato de que o usufrutuário aufere apenas o uso e a fruição da coisa (Gonçalves, 2012).

No ordenamento jurídico brasileiro, a concessão de uso pode ser efetuada pela Concessão de Direito Real de Uso (CDRU)), regulada pelo Decreto n ${ }^{\circ}$ 271, de 1967 (Brasil, 1967), pela Concessão de Uso Especial para fins de Moradia (CUEM) (e pelo Direito de Superfície. Os dois primeiros são destinados à concessão de uso de terrenos públicos, enquanto o último, de áreas privadas. Esses instrumentos são aceitos como garantia real nos contratos de financiamento habitacional e também devem ser registradas no Cartório de Imóveis. A PAD de Minas Gerais identificou apenas 6,9\% de incidência da emissão de concessão de uso dentre o total dos títulos emitidos.

A legitimação de posse é a proteção possessória daquele que, de fato, já exerce algum dos poderes inerentes à propriedade, por exemplo, o gozo ou o usufruto de um imóvel sem, no entanto, ser o seu efetivo proprietário. 0 instrumento da legitimação de posse foi criado pela Lei no 11.977, de 2009 (Brasil, 2009), no âmbito da regularização fundiária urbana, associado à demarcação urbanística. Esses instrumentos, segundo a lei, não implicam a alteração de domínio dos imóveis sobre os quais incidem o que somente se processará com a sua conversão em propriedade. Essa conversão poderá ser requerida após cinco anos do registro da legitimação de posse, considerando sua aquisição por usucapião.

A outorga da legitimação de posse incidiu em 7,1\% dos títulos emitidos, estando praticamente empatada com a concessão de uso. No entanto, deve-se fazer uma advertência no sentido de que a aplicação desses novos instrumentos ainda não é disseminada para regularização fundiária, e o próprio Ministério das Cidades tem poucas informações sobre a sua utilização. Assim, as respostas fornecidas pelos entrevistados podem se referir não exatamente ao instrumento previsto na Lei no 11.977 (Brasil, 2009), mas a outros instrumentos que reconhecem a posse exercida sobre áreas ocupadas, de modo a proteger a permanência das famílias nesses locais.

Em termos globais, os títulos de propriedade e as promessas de compra e venda são os documentos que respondem por $86 \%$ dos títulos emitidos, o que reflete a tradição brasileira em conferir grande importância à propriedade plena. No Brasil, além do valor de uso, a casa própria também desempenha a função de poupança financeira das famílias. Diante de mercados de capitais historicamente pouco desenvolvidos e longos períodos de instabilidade econômica, a propriedade imobiliária sempre constituiu reserva de valor e proteção do patrimônio acumulado pelas famílias. Na cultura do país, é importante deter o domínio pleno da propriedade para que dela se possa dispor conforme o interesse do seu proprietário.

Esses dois instrumentos também responderam pela maior participação no número de domicílios com terrenos próprios e documentos não registrados, respectivamente com 32,8 e 33,9\% do total. Porém, quando observados em suas próprias categorias, os títulos plenos de propriedade não registrados representaram apenas $5,1 \%$, enquanto as promessas de compra e venda apresentaram $20 \%$ sem registro.

Identifica-se como problema o fato de que, embora os títulos de concessão de uso e de legitimação de posse representassem, em conjunto, $14 \%$ dos títulos emitidos, um quarto deles não foi registrado. Chama a atenção as proporções desses títulos não registrados emitidos para apartamentos, as quais foram de $45 \%$ para a concessão de uso e $61 \%$ para a legitimação de posse. Esses casos podem estar ligados aos conjuntos habitacionais oriundos de programas habitacionais promovidos pelos governos. 
Tabela 7 - Domicilios próprios com terrenos próprios e títulos emitidos e não registrados por tipo de edificação e tipo de título

\begin{tabular}{lcccccc}
\hline \multirow{2}{*}{ Tipo do documento emitidodo } & \multicolumn{3}{c}{ Emitido por particular } & \multicolumn{3}{c}{ Emitido por ente público } \\
\cline { 2 - 7 } & Total & $\begin{array}{c}\text { Não } \\
\text { registrado }\end{array}$ & \% & Total & $\begin{array}{c}\text { Não } \\
\text { registrado }\end{array}$ & $\%$ \\
\hline Concessão de uso & 161.456 & 34.548 & $21,4 \%$ & 34.499 & 10.508 & $30,5 \%$ \\
Título pleno de propriedade & 1.603 .053 & 87.296 & $5,4 \%$ & 338.580 & 12.222 & $3,6 \%$ \\
Promessa de compra e venda & 460.138 & 90.055 & $19,6 \%$ & 46.840 & 13.604 & $29,0 \%$ \\
Legitimaç̃ón de posse & 159.893 & 26.847 & $16,8 \%$ & 34.496 & 23.875 & $69,2 \%$ \\
Total & $\mathbf{2 . 3 8 4 . 5 4 0}$ & $\mathbf{2 3 8 . 7 4 6}$ & $\mathbf{1 0 , 0 \%}$ & $\mathbf{4 5 4 . 4 1 5}$ & $\mathbf{6 0 . 2 0 9}$ & $\mathbf{1 3 , 2 \%}$ \\
\hline
\end{tabular}

Fonte: FJP (2014).

A Tabela 7 mostra os títulos quanto à sua emissão por ente público ou privado e ao registro. A maior parte dos títulos sem registro foi emitida por particulares, o que não surpreende, pois foram responsáveis por $81 \%$ do total dos títulos emitidos (títulos plenos e promessas de compra e venda), enquanto os títulos emitidos por ente público corresponderam apenas a $15,5 \%$ do total. No entanto, é maior a proporção dos títulos emitidos por ente público não registrado em relação aos emitidos por particulares. Exceto os títulos plenos de propriedade, os títulos de concessão de uso, legitimação de posse e promessa de compra e venda apresentaram as maiores proporções de falta de registro quando emitidos por ente público.

No caso dos títulos emitidos por particulares, os maiores problemas de falta de registro foram encontrados nos casos de concessão de uso e promessa de compra e venda. No entanto, tanto no caso de títulos emitidos por particular quanto por ente público, os títulos plenos de propriedade foram os que alcançaram a maior taxa de títulos registrados.

\section{Considerações finais}

0 presente artigo procurou descrever o quadro de insegurança da posse dos domicílios próprios urbanos do Estado de Minas Gerais, a partir dos dados da PAD, realizada pela Fundação João Pinheiro em 2013. Os dados mostraram que os domicílios próprios situados em terrenos não próprios, em terrenos próprios desprovidos de algum instrumento que proteja a posse da terra e que, mesmo quando emitidos, não foram registrados, assim como os domicílios cuja condição de ocupação é incerta, somaram 13\% do total dos domicílios urbanos do Estado. Houve predominância, com quase metade das ocorrências de problemas fundiários, dos domicílios titulados, mas que não foram registrados.

Constata-se que, mesmo que em alguns momentos problemas fundiários possam estar ligados a problemas de precariedade construtiva ou de acesso à infraestrutura, não há, necessariamente, uma correlação entre eles. A suposta interdependência entre esses problemas é inadequada, uma vez que são questões distintas que ocasionalmente podem estar sobrepostas, demandando, portanto, políticas públicas específicas. Nesse sentido, fica claro que os problemas fundiários urbanos e a consequente fragilização do direito constitucional de moradia se espalham entre os vários tipos de domicílios.

Devido à larga cadeia de efeitos que esses problemas podem ter sobre as condições habitacionais, sobre a economia e sobre a inserção das famílias na sociedade, especialmente as de baixa renda, ações mais efetivas de regularização fundiária, titulação e registro devem ser implementadas pelos governos. Para isso, é fundamental que a real dimensão e as especificidades do problema em termos nacionais sejam de conhecimento dos formuladores de políticas, de modo que se desenhem ações adequadas para o enfrentamento da questão fundiária urbana. Além disso, é necessário atentar para que as boas intenções não sejam contraproducentes, isto é, que o registro de um imóvel independa de obrigações alheias às questões fundiárias.

Os resultados aqui apresentados de maneira descritiva não esgotam as possibilidades de cruzamentos possíveis a partir das informações da PAD de Minas Gerais relativas à posse da terra urbana, especialmente 
considerando as dimensões e a complexidade desse Estado. Entender aspectos da insegurança da terra urbana vinculados a características regionais, a fatores socioeconômicos, em uma perspectiva mais micro, ou das características do próprio domicílio serão objetos de estudos futuros.

\section{Referências}

Acemoglu, D., \& Robinson, J. (2012). Why nations fail: the origins of power, prosperity and poverty. New York: Crown Business.

Boschi, R. R., \& Goldschmidt, R. I. (1970). Populações Faveladas do Estado da Guanabara. Relatório Final da pesquisa realizada pelo Instituto Universitário de Pesquisa do Rio de Janeiro em convênio com o Conselho de Desenvolvimento das Comunidades da Companhia Progresso do Estado da Guanabara 1969-1970. Rio de Janeiro: Sociedade Brasileira de Instrução.

De Soto, H. (1987). Economia subterrânea: uma análise da realidade peruana. Rio de Janeiro: Globo.

De Soto, H. (2001). O mistério do capital: por que o capitalismo dá certo nos países desenvolvidos e fracassa no resto do mundo. Rio de Janeiro: Record.

Frente Nacional de Prefeitos - FNP. (2014). Multi cidades: finanças dos municípios do Brasil. Vitória: Aequus Consultoria.

Fundação João Pinheiro - FJP. (2014). Pesquisa por Amostra de Domicílios de Minas Gerais - PAD (Boletim PAD-MG, ano 3, no. 7). Belo Horizonte: Centro de Estatística e Informações. Recuperado em 15 de janeiro de 2015, de http://www.fjp.mg.gov.br/index.php/docman/cei/ pad/502-boletim-pad-7-dezembro-19-11-2014-site-2/file

Gonçalves, C. R. (2012). Direito Civil Brasileiro: direito das coisas (7a ed). São Paulo: Saraiva.

Instituto Brasileiro de Geografia e Estatística - IBGE. (2011a). Censo Demográfico - 2010. Aglomerados subnormais, primeiros resultados. Rio de Janeiro: IBGE.

Instituto Brasileiro de Geografia e Estatística - IBGE. (2011b). Pesquisa de Informações Básicas Municipais 2011. Rio de Janeiro: IBGE. Recuperado em 30 de abril de 2015, de http://www.ibge.gov.br/home/estatistica/ economia/perfilmunic/2011/default.shtm

Brasil. (1967, 28 de fevereiro). Decreto № 271, de 28 de fevereiro de 1967. Dispõe sobre loteamento urbano, responsabilidade do loteador concessão de uso e espaço aéreo e dá outras providências. Brasília: Diário Oficial da União. Recuperado em 24 de março de 2015, de http:// www.planalto.gov.br/ccivil_03/Decreto-Lei/Del0271.htm

Brasil. (1979, 20 de dezembro). Lei 6.766, de 19 de dezembro de 1979. Dispõe sobre o parcelamento do solo urbano e dá outras providências. Brasília: Diário Oficial da União. Recuperado em 16 de fevereiro de 2015, de http://www. planalto.gov.br/CCIVIL_03/leis/L6766compilado.htm

Brasil. (2002, 11 de janeiro). Lei 10.406, de 10 de janeiro de 2002. Institui o Código Civil. Brasília: Diário Oficial da União. Recuperado em 24 de fevereiro de 2015, de http://www. planalto.gov.br/ccivil_03/leis/2002/L10406compilada.htm

Brasil. (2009, 8 de julho). Lei 11.977, de 7 de julho de 2009. Dispõe sobre o Programa Minha Casa, Minha Vida - PMCMV e a regularização fundiária de assentamentos localizados em áreas urbanas; altera o Decreto-Lei no 3.365, de 21 de junho de 1941, as Leis nos 4.380, de 21 de agosto de 1964, 6.015, de 31 de dezembro de 1973, 8.036, de 11 de maio de 1990, e 10.257, de 10 de julho de 2001, e a Medida Provisória no 2.197-43, de 24 de agosto de 2001; e dá outras providências. Brasília: Diário Oficial da União. Recuperado em 16 de fevereiro de 2015. de http://www.planalto.gov. br/ccivil_03/_ato2007-2010/2009/lei/l11977.htm

Maricato, E. (1999). A terra é um nó na Sociedade Brasileira. Também nas cidades. Cultura Vozes, 93(6), 7-22.

Moura, M., Bueno, R., \& Leony, L. (2009). How land title affects child labor? [Impact Evaluation Series, No. 37]. Policy Research Working Paper, 5010.

North, D. (1990). Institutions, institutional change and economic performances. Cambridge: Cambridge University Press.

North, D. (2005). Understanding the process of economic change. New Jersey: Princeton University Press.

Recebido: Maio 18, 2015

Aprovado: Jul. 22, 2015 